\title{
Are Trade Blocs Building or Stumbling Blocs?
}

\author{
Richard E. Baldwin \\ Graduate Institute of International Studies
}

Elena Seghezza

University of Genoa

\begin{abstract}
The stumbling-bloc argument asserts that regionalism hinders MFN tariff cutting. If this was of first-order importance over previous decades, we should detect this in the levels of the tariffs. Using tariff line data for 23 large trading nations we find that MFN and PTA tariffs are complements, not substitutes since margins of preferences tend to be low or zero for products where nations apply high MFN tariffs. One interpretation is that regionalism is neither a building nor a stumbling bloc. Sectoral vested interests are a 'third factor' that generates the positive correlation between MFN and PTA tariff levels.
\end{abstract}

- JEL Classification: F13, F15

- Key Words: Regionalism, Multilateralism, Stumbling Blocs, Trade Blocs

\section{Introduction}

Regionalism is sweeping the world trading system like wildfire while multilateral negotiations proceed at a glacial pace. This negative correlation raises the time-honoured question of whether regional trade agreements help or hinder global trade liberalisation. Until recently, much of the discussion was at the purely

\footnotetext{
*Corresponding address: Richard E. Baldwin; Graduate Institute of International Studies, 11a Avenue de la Paix 1202 Geneva, Switzerland, Tel: +41-22-908-5900, Fax: +41-22-733-3049, e-mail: Baldwin@ graduateinstitute.ch/Elena Seghezza; Department of Political and Social Sciences, University of Genoa, Largo Zecca 8/14, 16121 Genova, Italy, Tel: +39-010-2722529, Fax: +39-010-2099072, e-mail: seghezza@unige.it.

C2010-Center for International Economics, Sejong Institution, Sejong University, All Rights Reserved.
} 
theoretical level - the so-called stumbling bloc or building bloc debate (see the survey by Panagariya 1999 or the new book by Jagdish Bhagwati 2008). In this debate, trade blocs are stumbling blocs if they prevent or slow multilateral tariff cutting, while they are building blocs if they accelerate or at least do not hinder multilateralism. Numerous mechanisms have been presented to suggest that one or the other position is feasible/likely. These include Riezman (1985), Kennan and Riezman (1990), Krishna (1998), Freund (2000), Limão (2006), and Levy (1997).

In a series of highly innovative empirical papers, Nuno Limão and co-authors have begun to tackle this question empirically. His main approach is to see whether the size of tariff cuts in the Uruguay Round are related to preferential tariffs that existed pre-Uruguay Round. The stumbling bloc position suggests that nations should have cut their MFN tariffs less on products where they had regional preference in place while the building bloc position suggests the opposite. His findings support the stumbling bloc position. Since tariff cutting in the Uruguay Round was generally restricted to developed nations, Limão (2006) looks at the US while Karacavaoli and Limão (2008) find similar results for the EU. Estevadeordal, Freund and Ornelas (2008) do a similar exercise on Latin American data and find the opposite, i.e. that Latin American nations unilaterally cut their MFN applied tariffs most in the products where they had extended preferences.

These empirical studies aim directly at the stumbling/building bloc issue by measuring the MFN tariff cutting in products with and without preferences. This difference-in-difference strategy combines policy relevance with econometric sensibility. The approach, however, focuses on only part of the picture.

As part of the pre-agreed Uruguay Round agenda set in 1986, the US and the EU (inter alia) agreed to cut tariffs by as much as they had in the two previous Rounds, namely 30 per cent on average. The 30 per cent average is basically what was agreed in the deal that was eventually signed in 1994 (Finger and Schuknecht 1999). One interpretation of this commitment is that the overall US tariff cuts in the Uruguay Round were subject to a type of 'budget constraint'. If this is true, then to focusing on cross-product tariff cutting is incomplete. For example, it means that because of Limão's stumbling bloc effect was in effect in some products, the US had to cut tariffs by more in other products.

This line of thinking suggests that the levels of tariffs also hold information that can be used to evaluate the stumbling/building bloc question. If stumbling-bloc mechanisms have had a major impact on tariffs over the past decades, we should be able to detect this in the levels of the tariffs. Specifically, we should observe the 
highest MFN tariffs in the products where PTA tariffs are the lowest. After all, the juxtaposition of stumbling multilateralism and building regionalism is not new. Before its current manifestation in the Doha Round, it occurred in the early 1990s when regionalism in Europe and the Western Hemisphere was booming but the Uruguay Round was dormant. The same negative correlation between multilateral and regional deal making was observed in the mid-1970s when the Tokyo Round languished while the EU enlarged and simultaneously signed free trade agreements with all non-members in Western Europe.

There are two ways of exploiting the tariff level data - across nations and across products within nations. If regional trade liberalisation has - over past decades substantially slowed multilateral liberalisation, then we should see that the nations that engaged in an above-average amount of regional tariff cutting should have engaged in a below-average amount of MFN tariff cutting. Second, within nations, the tariff lines where nations cut tariffs the most preferentially should be the sectors where they cut their MFN tariffs the least. One way to express this is that if regionalism is a stumbling bloc, we should expect to see MFN and preferential tariffs as substitutes. If regionalism is a building bloc, we should expect to see MFN and preferential tariffs as complements.

This paper takes a first pass at confronting the tariff data for the world's largest traders with the substitutes-or-complements question. The next section, Section II, presents some key features of the data. Section III discusses an informal model of tariff formation which allows us to think about how we can structure our empirical work. Section IV presents our data, empirical strategies and results. Section V concludes.

\section{A First Look at the Data}

If cutting tariffs preferentially had a first-order-large impact on the choice of MFN tariffs, country by country, then we should be able to see the footprints in the level of nations' tariffs.

As a first pass, we consider the data with MFN and PTA tariffs averaged across all products for a broad range of countries. ${ }^{1}$ The facts are shown in Figure 1.

As a matter of definition, the PTA average cannot be higher than the MFN

${ }^{1}$ These are the top 50 exporting nations less those that have data problems as described in the next section. 
Figure 1. MFN and Preferential Tariff Averages by Nation, 2005

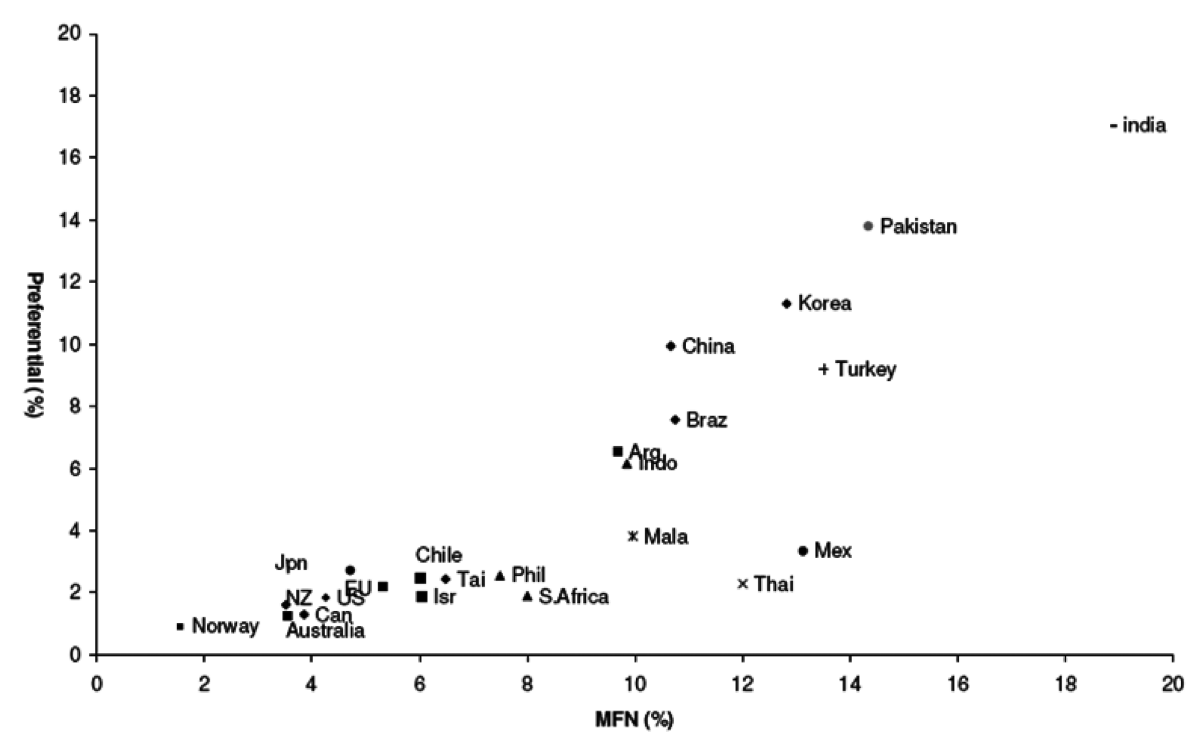

Source: WITS data base

average, so all points are below the 45 degree line. ${ }^{2}$ To highlight the complementsversus-substitutes dimension, consider what the relationship would look like if we have included only certain sub-set of nations. For example, if we took only Argentina, Brazil, Indonesia, Malaysia, Thailand and Mexico, we would see that nations with low preferential rates tended to have high MFN rates - i.e. that MFN and preferential tariffs where substitutes.

If we took only India, Pakistan, Norway, Canada and the EU, we would conclude that the two were complements - i.e. some nations cut tariffs a lot on a MFN and a preferential basis while others cut tariffs very little on either basis. When we include all 23 points in a simple-minded line-fitting exercise, the result is a positively sloped line with a coefficient of 0.8 and an $R$-squared of $71 \%$.

Plainly the 23 points have too little information in them to really understand the relationship between MFN and PTA tariffs. Two observations, however, are worth retaining. First, it seems that some nations have liberalised a great deal and these nations have done it both multilaterally and preferentially. Second, the figure shows clearly that we will have to control for country differences allowing the

\footnotetext{
${ }^{2}$ For both averages, we use simple un-weighted averages across all tariffs; since all PTA tariffs are less than or equal to the corresponding MFN tariff, line by line, the averages must respect the same inequality.
} 
identification to come from the variation across products for a given tariff-setting nation. One gets a great deal more econometric power by using tariff line data, but before turning to this, we consider a simple model to structure our thinking for the empirics.

\section{Simple Theoretical Considerations}

The formal modelling of tariff determination has a long tradition. For example early contributions, see the political support function approach of Hillman (1989) and Long and Vousden (1991), the formal lobbying approach of Findlay and Wellisz (1982), or the politically realistic objective function approach of Baldwin (1987). The theory is now dominated by the Grossman and Helpman (1994) Protection for Sale framework (PFS for short), which works in the lobbying approach and thus abstracts from electoral politics. The basic trade off is simple. Policy makers would rather not impose a tariff since it damages the economy, but they want the cash of lobbyists. In this paper, we work with a simplified version of the PFS model.

\section{A. Basic Assumptions}

To focus on the political economy aspects, we assume an extremely simple underlying economy. Preferences of all factor owners are identical and quasi-linear so as to eliminate general equilibrium considerations stemming from income effects. We also assume preferences are separable sector-by-sector so as to eliminate cross-price effects on demand. Thus the typical direct utility function and corresponding indirect utility function are:

$$
u=c_{0}+\sum_{i=1}^{n} u_{i}\left[c_{i}\right], v=E+\sum_{i=1}^{n} s_{i}\left[p_{i}\right]
$$

where $n$ is the number of non-numeraire sectors, the $u_{i}$ sub-utility functions for each non-numeraire sector, $E$ is expenditure, $s_{i}\left(p_{i}\right)$ are sector-specific consumer surplus functions, $c_{0}$ is consumption of the untaxed, numeraire good and $c_{i}$ is consumption of typical good $i .^{3}$

To simplify the supply side, we adopt a Ricardo-Viner set-up, so labour's price

\footnotetext{
${ }^{3}$ Note that consumer surplus perfectly captures the welfare impact of price changes. Indeed, the typical indirect utility function is just income, denoted as $E$, plus the sum of sector-specific consumer surplus measures, $s_{i}\left(p_{i}\right)$.
} 
is pinned down by productivity in the numeraire sector and each sector-specific factor is paid its Ricardian rent. This means that $E$ for a typical consumer equals her labour income $w L$ plus her share of tariff revenue, $r$, plus the payment to whatever sector-specific factors she owns.

In the PFS framework, the government's objective function $\Omega$ is a weighted sum of standard utilitarian social welfare function $W$, and lobbying contributions, $\Omega=a W+\sum_{i \in \Lambda} C_{i}\left[p_{i}\right]$ where capital lambda, $\Lambda$, is the set of sectors that are organised politically (and thus can make political contributions) and $C_{i}$ is the contribution of sector $i$. Here we assume:

$$
\Omega=W[\tau]+\Sigma_{i \in \Lambda} \Pi_{i}[\tau]
$$

where $W[\tau]$ is the utilitarian welfare index and $\Pi_{i}$ is the rents earned by special interest groups in sector $i$; as before, $\Lambda$, is the set of sectors that are organised politically. This has the drawback that we do not explicitly model how the rents of special interest groups affect policymakers' utility (PFS assumes it is as if the cash is handed directly to policymakers). The advantage is that it may be appropriate to a wider range of political systems where 'lobbying' is not cash-based as in the US.

\section{(1) Politically Optimal Tariff}

The first order condition for the choice of the tariff in a typical sector that is organised is:

$$
0=W^{\prime}[\tau]+\sum_{j \in \Lambda} \Pi_{i}^{\prime}[\tau]
$$

where the first term can be thought of as the marginal cost of raising the tariff from its optimal level and the second term can be viewed as the marginal benefit (to the government) of doing so. Using the analogy of the supply curve as the marginal cost of production and the demand curve as the marginal utility of consumption, we call the first term the protection supply curve and the second term the protection demand curve.

The protection supply and demand curves are plotted in Figure 2. The demand curve is upward sloped since the amount of domestic production to be protected on the margin rises with the level of the tariff. The supply curve is upward sloped since the damage to the economy rises with the level of the tariff when the tariff is beyond the optimal tariff level. It intersects the x-axis at the naïve 'optimal' tariff 
Figure 2. Supply and Demand for Protection

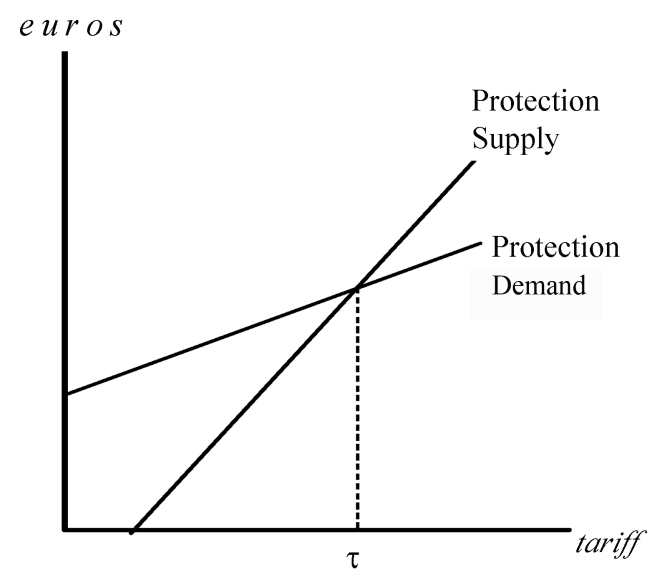

(i.e. welfare maximising). The intersection of the two curves (drawn linearly for graphically convenience) is the solution to the government's first order condition.

\section{B. Impact of an Exogenous PTA}

The stumbling and building bloc literature generally frames the policy experiment as adding regional trade agreements, more or less exogenously, to the existing MFN system (Panagariya 1999). In this framing of the question, a PTA gets signed thereby raising the question of whether nations who would have agreed to cut MFN tariffs prior to the PTA will still agree to cut them after the PTA (see, e.g., Levy 1997, Freund 2000, and Limão 2006). This is not the only approach and we consider another below, but we start with this mainstream framing of the helps/ hinders question. ${ }^{4}$

Formally, we add the preferential tariff as an argument to the $W$ and $\Pi$ in equation 2 . The idea is that utility now depends upon the preferential rate as well since imports from the partner may enter at a lower price, leading to a market adjustment that changes the function relationship between the MFN tariff and welfare. As concerns the rents, we add the preferential tariff assuming that imports from partner may not be perfect substitutes for imports from the rest of the world, so the special interest groups care about the two tariffs independently. ${ }^{5}$

\footnotetext{
${ }^{4}$ There is some anecdotal support for taking PTA as an exogenous addition. PTAs are often the result of high-level politics involving the heads of state of the two partners. Moreover, although there is always some room for excluded sectors, in most cases the agreement will lead to across the board preferential tariff cuts so the sector-by-sector logic of the politically optimal tariff discussed above does not apply. ${ }^{5}$ If imports from all sources are perfect substitutes, all that matters for rents is the domestic price.
} 
Figure 3. Supply and Demand Shifts with a PTA

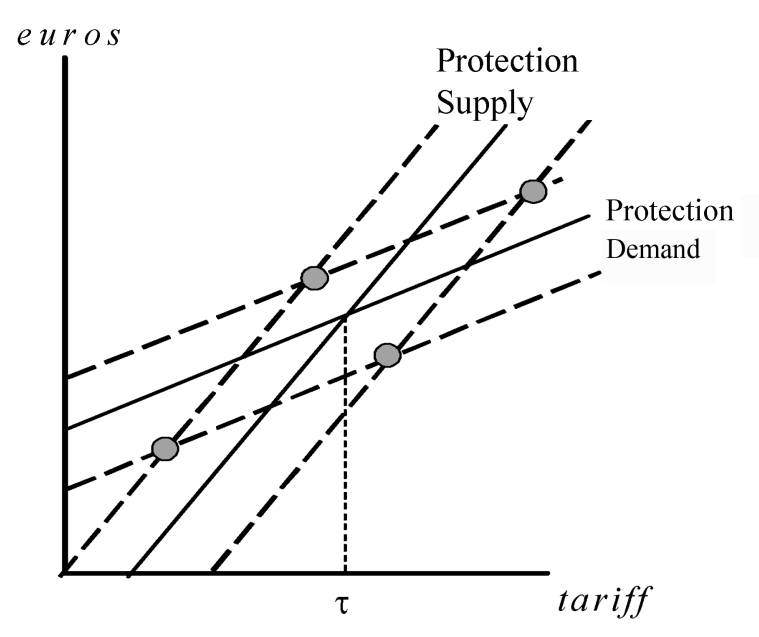

Adding in the preferential tariff - or more specifically lowering the tariff charged on imports from the PTA partner - will shift the protection demand and supply curves. It is not clear, however, which way the shift will go. In the case of Europe's Common Agricultural Policy, the liberalisation of internal EU trade in food clearly raised the demand for external protection. This would correspond to a shift out of the protection demand curve. However, the preferential liberalisation may force out many domestic firms that would have otherwise demanded MFN tariffs and so the protection demand curve might shift in.

On the supply side, the shift could again go either way. The possibility of imports from the partner may lower the cost of raising the MFN tariff so the protection supply curve may shift down/out. Alternatively, the resulting trade diversion and attendant sourcing from may raise the distortionary effect of any given level of the MFN tariff and so the protection supply curve may shift up/back.

The net effect on the politically optimal MFN tariff is ambiguous as shown in . There are four possible cases involving the various in-or-out shifts of the two curves. The message of the figure is that signing a PTA may raise or lower the politically optimal MFN tariff. The matter cannot be solved by logic. It is an empirical question.

\section{MFN Tariffs Exogenous}

An alternative view is that we can take the MFN tariffs as given. One argument is that MFN tariffs are changed only episodically since multilateral trade 
negotiations happen so rarely and then the results are phased in over a 10 year period. Preferential tariffs, however, are set whenever a nations signs a PTA, which, in recent years, has happened quite frequently for many nations.

Adopting this tact, we may think that nations decide whether to grant the preferential in each tariff line taking as given the MFN tariff. This of course turns the building/stumbling bloc logic on its head, but it may capture how many preferences are granted. In this approach, MFN and preferential rates are substitutes if nations tend to grant the biggest preferences where they have the highest MFN tariffs. For example, if - following the logic of Limão (2006) - the US is using trade preferences to 'buy' compliance with its anti-drug policy, or some foreign policy objective, then the 'purchasing power' of the preference rises with the MFN tariff. We should, therefore, see the US putting on the lowest preferential rates on tariff lines where there are high MFN rates. By contrast, if multilateral and preferential rates are complements - for example, strong vested interests in particular sectors can prevent any sort of tariff cuts in their sector - we should see the lowest preferential rates where the multilateral rates are lowest.

\section{Empirical Predictions}

Figure 4 illustrate the sort of data that would be generated if the stumbling bloc logic is in operation versus the data that would be generated by the building-bloc logic. This schematic diagram plots the MFN tariffs on the vertical axis and preferential tariffs on the horizontal. Using the shaded rectangles to depict data clusters, the left panel shows what the situation would be if MFN and PTA tariffs

Figure 4. Intuition for the Strong Correlation between MFN and Preferential Rates
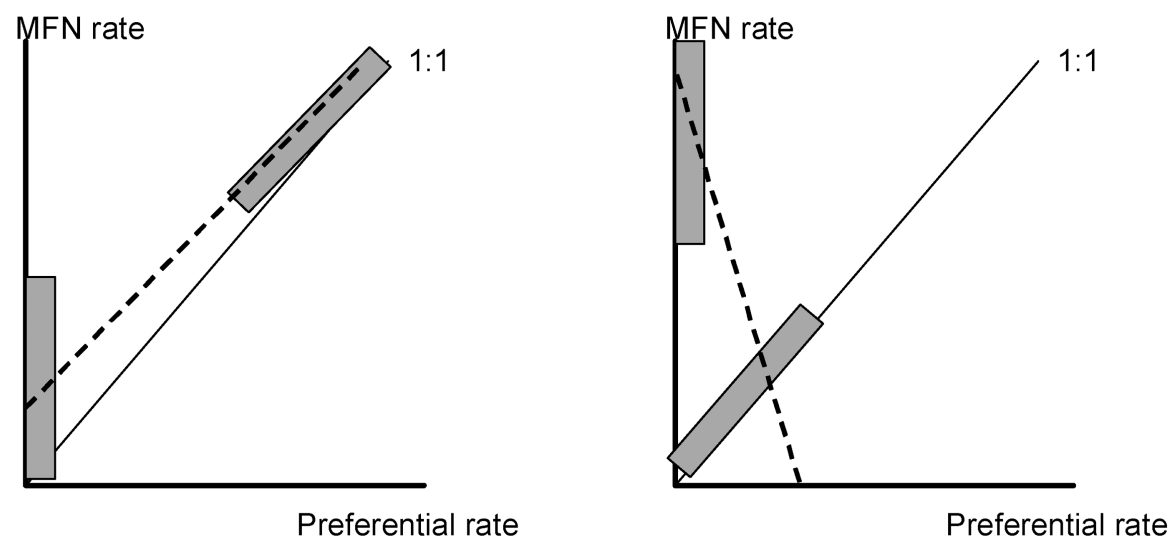
were complements, i.e. the building bloc logic was dominant. The data is shown as massed along the 45 degree ray for products with high MFN tariffs, and along the vertical axis (duty free preferential trade) for products that have low MFN tariffs. The dashed line, which depicts the notional fitted line, has a slope that is less than unity and a positive y-axis intercept.

The right panel shows the sort of data we should expect if the stumbling bloc logic were dominant, i.e. MFN and PTA tariffs were substitutes. Here countries would tend to grant preferences in the country-tariff-line observations with high MFN rates. The shaded blocs are massed on the vertical axis since countries would maintain high MFN tariffs on goods as a substitute for low PTA tariffs they extended. For products with low MFN tariffs, there would be little use in extending preferences, so the low MFN tariffs would be massed on the $45^{\circ}$ line. The regression line in this case would have a positive intercept and a slope either negative, or positive and bigger than one.

\section{Empirical Analysis}

The simple theory discussed above captures the notion that preferential and MFN tariffs may be complements or substitutes, with substitutes suggesting that the stumbling bloc logic has been strongest, and complements suggesting the building bloc logic.

To look at this issue, we examine the cross-section relationship between MFN and preferential rates at the detailed product level for a wide range of nations. We think it is important to work with tariff line data - rather than aggregates - since this allows us to avoid standard aggregation biases. We also think it is important to work with a broad set of nations to study the impact of PTAs on the world trade system. Of course both of these desiderata rule out some of the more sophisticated panel techniques, like those of Limão (2006). In compensation, we can look at a broad range of nations.

\section{A. The Data}

The data we work with is at the most detailed level possible - the tariff line level, which is up to 10 digits in HS system depending upon the nation. It is from the TRAINS database accessed through WITS for the year 2005. For each country, the MFN ad valorem tariffs is well defined, but for preferential tariffs we have to address the fact that most nations have more than one vector of preferential tariffs; 
Table 1. Summary Statistics

\begin{tabular}{lcccccc}
\hline Variable & Observations & Mean & Std dev & Min & Max & Number of Zeros \\
\cline { 2 - 6 } MFN rate & $1,430,933$ & 8.40 & 16.28 & 0 & 1235 & 445,768 \\
Preferential rate & $1,430,933$ & 5.34 & 15.34 & 0 & 887.4 & 837,305 \\
GAP (MFN-PTA) & $1,430,933$ & 3.06 & 7.11 & 0 & 1235 & 821,320 \\
\hline
\end{tabular}

Source: Authors' calculations.

the preferential tariffs applied differs by partners. Some of these preferences are very minor - for example, New Zealand applies MFN rates to British exports of all goods except those falling in 9 tariff lines (out of a total of 7432). For these minor agreements, the PTA tariff vector is almost identical to the MFN vector. Since we do not believe that such minor agreements tell us much about the underlying political economy process, we excluded them. Note that this exclusion shades the outcome against finding that MFN and PTA tariffs are complements. ${ }^{6}$

We start with data for the top 50 exporters in the world in 2005 as defined by the WTO's website. For data reasons, however, we are forced to drop a number of nations. Some of them are not WTO members and thus do not have MFN rates (the Russian Federation, Vietnam, Ukraine, Iran), others are dropped since they are oil exporters and thus are not setting tariffs according to the usual political economy logic (United Arab Emirates and Saudi Arabia). We also drop nations where all MFN rates are zero (and therefore all preferential rates are zero); these are: Hong Kong and Singapore. Switzerland is dropped since most of its tariffs are specific and thus not comparable. The 23 nations left are Argentina, Australia, Brazil, Canada, Chile, China, European Union, India, Indonesia, Israel, Japan, Korea, Malaysia, Mexico, New Zealand, Norway, Pakistan, the Philippines, South Africa, Taiwan, Thailand, Turkey, and the United States. Table 1 shows some summary statistics for our data.

\section{B. Tariff-line Level Analysis}

Our question is a simple one - are MFN and PTA tariffs complements or substitutes? - so we start with a very simple regression specification. The estimated equation is:

$$
\mathrm{MFN}_{g p m}=\alpha+\beta \mathrm{PTA}_{g p m}+\gamma_{0} \text { Dchapter }_{g m}+v_{g m}
$$

${ }^{6} \mathrm{We}$ exclude any preferential tariff vector that grants preferences for less than $2 \%$ of the MFN tariff lines. 
where $g$ indexes the 23 countries, $p$ indexes the preferential agreement (for each country, each preferential agreement is stacked one after the other) and $m$ indexes the tariff line. ${ }^{7}$ Dchapter $_{g m}$ are 14 dummies for the main HS chapter aggregations (animal, vegetables, foodstuffs, mineral products, chemicals, plastics, raw hides, skin and leather, wood, textile, footwear, stone and glass, metals, machinery and transportation equipment). ${ }^{8}$ The error term, $v_{g m}$, may contain a common group effect, $c_{g}$, that is $v_{g m}=c_{g}+u_{g m}$.

Since we are working at the tariff line level, we have to decide what to do with the tariff lines where the MFN rate is zero (around a third of the observations). A first option, following Limão (2006), is to throw them away on the argument that one cannot grant a preference in such cases. The second option is to keep these observations since they are the outcome of the data generating process we are trying to identify. We shall try both.

\section{(1) Only Positive MFN Tariff Observations}

The first cut is to run a pooled OLS that views all observations as generated by the same process. The first column of Table 2 reports the results with only chapter dummies included. What we see is that MFN and preferential tariffs are positively correlated - the coefficient is 0.90 - with a good fit. Before turning to more subtle estimators, it is worthwhile considering what is driving this result.

Once we have eliminated the tariff lines with zero MFN rates, we find that 375,552 of the 985,165 country-tariff-line observations have the same rate for MFN and preferential, i.e. for a great many products (38\%), nations grant no preferences at all. ${ }^{9}$ In the country-tariff-line observations where preferences are granted, two-thirds of the preferential rates are zero.

The OLS regression strongly suggests that the data resembles the left panel of Figure 4-i.e. a situation where MFN and preferential rates are generally complements, not substitutes. The high $R$-square is probably accounted for the fact that MFN and preference rates are really not that different, or in other words tariff

\footnotetext{
${ }^{7}$ This number varies from country to country from a minimum of 5,417 for Thailand to a maximum of 12,733 for the EU, on average there are more than 9,000 tariff lines per country.

${ }^{8}$ We have also tried a finer classification (97 dummies representing the HS2 classification level), but results do not change.

${ }^{9}$ Fraction of products that receive no preferences by country (when $\mathrm{mfn}>0$ ): Argentina 14\%; Australia $27 \%$; Brazil 11\%; Canada 25\%; Chile 11\%; China 92\%; Eu 27\%; India $83 \%$; Indonesia $54 \%$; Israel 16\%; Japan 38\%; Korea 68\%; Malaysia 18\%; Mexico 4\%; New Zealand 5\%; Norway 14\%; Pakistan 94\%; Philippines 10\%; South Africa $2 \%$; Taiwan $9 \%$; Thailand $10 \%$; Turkey $20 \%$ and USA $22 \%$.
} 
Table 2. Regressions of MFN on PTA (Tariff Lines with Positive MFN Rates)

\begin{tabular}{cccc}
\hline & Pooled OLS & Random Effects $^{1}$ & Fixed Effects $^{1}$ \\
\cline { 2 - 4 } PTA tariff & 0.90 & 0.92 & 0.92 \\
& $(0.0020)$ & $(0.0019)$ & $(0.0019)$ \\
Constant & 5.19 & 6.32 & 4.90 \\
$R$-squared overall & $(0.029)$ & $(0.82)$ & $(0.03)$ \\
& 0.81 & 0.81 & 0.82 (within) \\
\hline
\end{tabular}

Notes: Robust standard errors in parentheses. ${ }^{1}$ The number of clusters is 23 ; the number of observations is 985,165 . Chapter dummies not reported.

preferences are not all that important in the 2005 data for a broad range of nations.

The pooled OLS estimator ignores the within cluster correlation of the errors. In the presence of correlation within clusters, the pooled OLS estimator is consistent but not efficient. Since we are dealing with nations of widely differing average tariffs, the amount of within cluster correlation can be substantial, so the OLS standard errors can be misleading. Of course with almost a million observations even an inefficient estimator may be good enough, but it is important to undertake the standard adjustments to verify this conjecture.

One way to correct for this problem and get efficient estimates is to run the random effects estimator. This estimator assumes more stringent hypothesis about the errors. In particular it assumes strict exogeneity, that is, a tariff line error cannot be correlated with the explanatory variables on a different tariff line of the same country. The results are reported in the second column of Table 2 . We see that little changes in terms of the point estimates.

We also try the fixed effects estimator, which, in our data set, amounts to adding country dummies. The third column of Table 2 shows that the fixed effect estimator produces coefficients that are quite similar.

\section{(2) Robustness Tests}

So far we have pooled data from all 23 nations. This fact may give rise to various concerns. First, one can argue that small countries should not have much bearing on the systematic issue of PTAs and multilateral liberalization. The first column in Table 3 weighs each observation for the GDP of the country; in this way big countries count more.

Second, we have used the most disaggregated tariff data available for each 
Table 3. Robustness Tests - Weights for GDP, Number of Tariff Lines, Number of Preferential Agreements

\begin{tabular}{cccc}
\hline Weights: & GDP & Tariff Lines & PTA \\
\cline { 3 - 4 } PTA Tariff & 0.87 & 0.90 & 0.91 \\
& $(0.00)$ & $(0.0005)$ & $(0.0012)$ \\
Constant & 3.76 & 5.20 & 5.22 \\
Adj. $R$-squared & $(0.029)$ & $(0.036)$ & $(0.093)$ \\
\hline
\end{tabular}

Notes: Pooled OLS estimations. Robust standard errors in parenthesis. Dummy variables not reported.

country. ${ }^{10}$ Not all countries apply tariffs at the HS10 level, so the number of tariff lines differs across countries. The second column in Table 3 weighs each observation for the number of tariff lines of the country in order to give less weight to countries with a more detailed classification.

Third, the number of Preferential Agreements is different from country to country. Since preferences given by a single country are not aggregated, if a good enters in two preferential agreements that good counts as two observations. The third column in Table 3 weighs each observation for the number of Preferential Agreements of the country in order to give less weight to countries with many preferential agreements.

We find that our specification is robust: the coefficient of PTA is always significant, positive and similar in size to that in Table 2.

Another kind of robustness test asks whether it is appropriate to consider all the observations with positive MFN. It may be worth limiting part of the analysis to MFN tariffs above a certain threshold. The point is to limit cases where preferential

Table 4. Robustness Tests - MFN Observations above a Threshold

\begin{tabular}{ccccc}
\hline & MFN $>10$ & MFN $>20$ & MFN $>30$ & MFNPTA \\
\cline { 2 - 5 } PTA tariff & 0.87 & 0.90 & 0.86 & 0.83 \\
& $(0.0031)$ & $(0.0032)$ & $(0.0050)$ & $(0.0063)$ \\
constant & 7.40 & 15.75 & 79.40 & 7.34 \\
Number Obs. & $(0.063)$ & $(0.093)$ & $(2.62)$ & $(0.039)$ \\
Adj. $R$-squared & 422,462 & 64,509 & 26,883 & 609,613 \\
& 0.80 & 0.80 & 0.79 & 0.25 \\
\hline
\end{tabular}

Notes: Pooled OLS observations. Robust standard errors in brackets.

\footnotetext{
${ }^{10} \mathrm{We}$ have not done cross-country variations at this detailed level. Consequently, even if the HS classification is internationally harmonized only up to HS6, there is no risk of using the same code for different goods.
} 
tariffs are restricted to be low. Table 4 shows results for subsamples where MFN is greater than 10, 20 and 30. Moreover, it also shows results for the subsample that discards all observations where MFN=PTA.

We find that our specification is robust with regard to these changes: the PTA coefficient is always significant, positive and comparable in magnitude to those in Table 2.

Finally, our results may depend on the econometric specification. When MFN tariffs are regressed on preferential tariffs there could be a bias in finding a positive relationship. To address this problem we first regress MFN tariffs on a preference indicator (PI) equal to 1 if a preference is granted, and 0 otherwise. Then, we regress MFN tariffs on the preference indicator and its interaction with the preferential tariff, so the latter variable is equal to zero if no preference is granted, and it is equal to the preferential tariff otherwise. The estimated equations are:

$$
\begin{gathered}
\operatorname{MFN}_{g p m}=\alpha_{0}+a_{1} \mathrm{PI}+\gamma_{0} \text { Dchapter }_{g m}+v_{g m} \text { or } \\
\mathrm{MFN}_{g p m}=\alpha_{0}+\alpha_{1}(\mathrm{PI} \text { PTA })_{g p m}+\gamma_{0} \text { Dchapter }_{g m}+v_{g m}
\end{gathered}
$$

Table 5 gives the results. In the first column MFN tariff is regressed on the preference indicator. The coefficient of this variable is negative: goods where a preference is granted have in general a lower MFN tariff.

In the second column MFN tariff is regressed on the preference indicator and on its interaction with the preferential tariff. The coefficient of the preference indicator is still negative, while the coefficient of the interaction of the preference indicator with the preferential tariff is positive and less than one: for the subset of products

Table 5. MFN on a Preference Indicator

\begin{tabular}{ccc}
\hline & $\begin{array}{c}\text { Preference } \\
\text { Indicator }\end{array}$ & $\begin{array}{c}\text { Preference Indicator } \\
\text { and PTA }\end{array}$ \\
\cline { 2 - 3 } Preference Indicator & -5.54 & -7.72 \\
Preference Indicator & $(0.039)$ & $(0.041)$ \\
Multiplied for PTA & - & 0.79 \\
Constant & 14.11 & $(0.006)$ \\
Adj. $R$-squared & $(0.039)$ & $(0.038)$ \\
& 0.10 & 0.14
\end{tabular}

Notes: Robust standard errors in brackets. Number of observations. 985165. Preference Indicator $=1$ if a preference is given, 0 otherwise. 
that do have preferences, MFN and PTA tariffs are complements.

After these robustness tests we can safely return to our specification and do a cross-country comparison for groups of countries. For example, do rich and poor countries behave differently?

\section{(3) Rich and Poor Nations}

It is easy to think that the political economy process is quite different in rich and poor nations. Nations that declared themselves as developed in the GATT/WTO are required to respect a number of disciplines on their tariffs, such as bindings.

During the eight rounds of multilateral trade negotiations conducted by the GATT/WTO, developing nations were largely free-riders from the point of view of tariff cutting. Basically, only developed nations engaged in reciprocal tariff cutting in these Rounds.

Given these differences, it seems natural to re-run our regressions on separate developed- and developing-nation samples to determine if the mechanism is one of building blocs in both set of countries. The results are shown in .

Again we find that MFN and preferential rates are complements. The intercept, however, is higher for the developing nations (their tariffs are higher on average). ${ }^{11}$

It is worthwile, at this point, to re-run our regression country by country to determine if there are important differences between them. Table 7 shows the results.

The first part of the table shows our preferred specification. For all countries PTA is positively correlated with MFN; its coefficient is significantly lower than one for the entire sample but the Philippines and Thailand. The evidence suggests

Table 6. Developed and Developing Nation Samples (Pooled OLS on All the Observations).

\begin{tabular}{ccccccc}
\hline & \multicolumn{3}{c}{ Developed Countries $^{(1)}$} & \multicolumn{3}{c}{ Developing Countries } \\
& Coefficient & s.e & $P>t$ & Coefficient & s.e. & $P>t$ \\
\cline { 2 - 7 } PTA tariff & 0.97 & 0.0017 & 0.0 & 0.92 & 0.0018 & 0.0 \\
Constant & 1.42 & 0.014 & 0.0 & 4.19 & 0.029 & 0.0 \\
$R$-squared & 0.67 & & & 0.84 & & \\
Countries & 7 & & & 16 & & \\
Observations & 506,333 & & & 924,600 & &
\end{tabular}

Notes: Standard errors (s.e.) corrected for heteroschedasticity. Chapter dummies not reported. ${ }^{(1)}$ Australia, Canada, EU, Japan, New Zealand, Norway, USA.

\footnotetext{
${ }^{11}$ The mean MFN tariff for rich country is 3.54 and for poor countries is 11.06 .
} 
Table 7. PTA Country by Country

\begin{tabular}{|c|c|c|c|c|c|c|c|c|c|c|}
\hline Country & PTA & Constant & $\begin{array}{c}R- \\
\text { squared }\end{array}$ & $\begin{array}{l}\text { Preference } \\
\text { Indicator }\end{array}$ & $\begin{array}{l}\text { Con- } \\
\text { stant }\end{array}$ & $\begin{array}{c}R- \\
\text { squared }\end{array}$ & $\begin{array}{l}\text { Preference } \\
\text { Indicator }\end{array}$ & $\begin{array}{l}\text { Pref. Ind. } \\
\text { x PTA }\end{array}$ & $\begin{array}{l}\text { Con- } \\
\text { stant }\end{array}$ & $\begin{array}{c}R- \\
\text { squared }\end{array}$ \\
\hline Argentina & 0.60 & 10.81 & 0.64 & -0.42 & 17.19 & 0.42 & -4.82 & 0.66 & 15.95 & 0.59 \\
\hline Australia & 0.25 & 5.08 & 0.51 & $0.11^{*}$ & 5.42 & 0.44 & -0.18 & 0.42 & 5.57 & 0.48 \\
\hline Brazil & 0.52 & 11.02 & 0.62 & -0.13 & 16.64 & 0.43 & -3.32 & 0.53 & 15.70 & 0.54 \\
\hline Canada & 0.27 & 6.13 & 0.50 & $0.008^{* * *}$ & 6.58 & 0.43 & -0.22 & 0.28 & 6.69 & 0.44 \\
\hline Chile & 0.04 & 5.89 & 0.04 & -0.094 & 6.08 & 0.02 & -0.12 & 0.01 & 6.08 & 0.02 \\
\hline China & 0.88 & 1.53 & 0.88 & 0.65 & 13.16 & 0.24 & -2.49 & 0.60 & 13.16 & 0.25 \\
\hline $\mathrm{Eu}$ & 0.39 & 5.46 & 0.61 & -0.66 & 7.42 & 0.51 & -1.14 & 0.44 & 7.44 & 0.55 \\
\hline India & 0.81 & 4.40 & 0.85 & -0.63 & 15.11 & 0.37 & -1.72 & 0.17 & 15.18 & 0.37 \\
\hline Indonesia & 0.83 & 4.29 & 0.79 & $-0.26^{* * *}$ & 8.59 & 0.27 & -3.19 & 1.36 & 9.02 & 0.29 \\
\hline Israel & 0.87 & 11.45 & 0.77 & $0.31^{* * *}$ & 11.86 & 0.38 & $-0.38^{* * *}$ & 0.45 & 12.46 & 0.38 \\
\hline Japan & 0.70 & 3.81 & 0.78 & -2.16 & 6.39 & 0.41 & -2.32 & 0.13 & 6.5 & 0.41 \\
\hline Korea & 0.99 & 2.67 & 0.97 & -6.27 & 10.00 & 0.14 & -5.55 & $-0.43^{* * *}$ & 9.77 & 0.14 \\
\hline Malaysia & 0.83 & 12.98 & 0.73 & 6.87 & 13.17 & 0.31 & -5.14 & 2.65 & 12.72 & 0.32 \\
\hline Mexico & 0.76 & 12.26 & 0.48 & -10.24 & 24.45 & 0.14 & -12.17 & 0.58 & 24.89 & 0.20 \\
\hline $\begin{array}{l}\text { New- } \\
\text { Zealand }\end{array}$ & 0.14 & 6.72 & 0.03 & -0.99 & 7.82 & 0.03 & -1.08 & $0.13^{* * *}$ & 7.82 & 0.03 \\
\hline Norway & 0.77 & 139.8 & 0.90 & 17.17 & 424.41 & 0.70 & -12.78 & 0.76 & 418.73 & 0.77 \\
\hline Pakistan & 0.92 & 1.39 & 0.93 & -2.98 & 12.96 & 0.20 & -4.49 & 0.47 & 12.93 & 0.21 \\
\hline Philippines & 1.16 & 3.27 & 0.60 & 2.29 & 3.49 & 0.29 & -1.26 & 1.71 & 4.62 & 0.58 \\
\hline $\begin{array}{l}\text { SouthAf- } \\
\text { rica }\end{array}$ & 0.37 & 15.79 & 0.43 & 3.12 & 14.45 & 0.36 & $1.49^{* *}$ & 0.39 & 14.25 & 0.44 \\
\hline Taiwan & 0.42 & 4.11 & 0.26 & 1.64 & 3.51 & 0.24 & $0.039^{* * *}$ & 0.45 & 4.12 & 0.26 \\
\hline Thailand & 1.00 & 9.02 & 0.37 & 7.61 & 3.45 & 0.31 & $0.54^{* * *}$ & 2.49 & 6.03 & 0.44 \\
\hline Turkey & 0.84 & 3.21 & 0.90 & -14.29 & 17.39 & 0.53 & -17.08 & 0.51 & 20.14 & 0.53 \\
\hline USA & 0.91 & 3.70 & 0.69 & -1.69 & 5.81 & 0.07 & -2.62 & 0.72 & 6.57 & 0.09 \\
\hline
\end{tabular}

Notes: Dummy variables not given. Robust standard errors. Stars mean not significant: ${ }^{* * *}=p$-value $>0.10$, ${ }^{* *} p$-value $>0.05,{ }^{*}$ p-value $>0.01$. When nothing is given it is significant at the $99 \%$ All slope coefficients but those of Thailand and the Philippines are significantly lower than one.

that MFN and PTA are complements for almost all countries in the sample.

This result is robust to a change in specification. In the second part of the table MFN is regressed on the preference indicator used in Table 5, We recall that this indicator is equal to one if a preference is granted, zero otherwise. Its coefficient is negative - meaning that MFN is lower on average when PTAs are granted - in $60 \%$ of the countries. Out of 23 countries, in three cases the preference indicator is not significant (Canada, Indonesia and Israel). Its coefficient is negative for Argentina, Brazil, Chile, EU, India, Japan, Korea, Mexico, New Zealand, Pakistan, Turkey and the United States. Its coefficient is positive - suggesting a stumbling bloc effect - for Australia, China, Malaysia, Norway, the Philippines, South Africa, Taiwan, Thailand. 
These results are consistent with the findings of Estevadeordal et al. (2008) that preferential agreements are building blocs to external trade liberalization in Latin America: in all Latin American countries the preference indicator has a negative sign.

The third part of the table regress MFN on the preference indicator and on its interaction with the preferential tariff. Adding the interaction between the preference indicator and the PTA variable reinforces our results. Now the preference indicator, when significant, is always negative (it is insignificant only in three cases: South Africa, Taiwan and Thailand). The interaction term, when significant, is always positive (not significant for Korea, and New Zealand) and generally lower than one (it is higher than one only for Indonesia, Malaysia, the Philippines and Thailand), suggesting that countries tend to grant preferences in goods with low MFN tariffs.

This analysis at the country level suggests MFN and PTA tariffs are generally complements. There is evidence of stumbling blocs only for the Philippines and Thailand.

\section{(4) Including All Tariff Observations}

Throwing away all the tariff-lines with zero MFN rates clearly shades the outcome towards finding that MFN and preferential tariffs are substitutes since it excludes a large set of observations where MFN and PTA tariffs are both zero. Here we re-run our regressions with the zeros put back into the data sample.

The results, shown in Table 8, reveal that the treatment of zeros does not matter much. For all the estimators, the coefficients are qualitatively similar to those of Table 2. The constants are positive and the PTA coefficients are lower than one. While the coefficients are still less than unity, they generally are a little bit larger. The reason is that adding the mass of zero-zero observations pulls down the y-axis

Table 8. Regressions of MFN on PTA (All Observations)

\begin{tabular}{cccc}
\hline & Pooled OLS & Random Effects & Fixed Effects \\
\cline { 2 - 4 } PTA & 0.94 & 0.94 & 0.94 \\
& $(0.0012)$ & $(0.0013)$ & $(0.0013)$ \\
Constant & 3.07 & 3.74 & 3.07 \\
$R$-squared overall & $(0.019)$ & $(0.54)$ & $(0.018)$ \\
& 0.82 & 0.82 & 0.81 (within) \\
\hline
\end{tabular}

Notes: Robust standard errors in brackets. Number of observations is 1,430,933; number of clusters is 23 . Chapter dummies not reported. 
intercept and raises the slope a bit (see left panel of Figure 4).

\section{Respecting the Inequality Constraint}

The simple regressions reported above do not respect the inequality constraint between MFN and PTA tariffs. Here we manipulate the basic empirical model in a way that allows us to impose this feature on the regressions. Subtracting PTA from both sides we get:

$$
(\mathrm{MFN}-\mathrm{PTA})_{g p m}=\alpha+(\beta-1) \mathrm{PTA}_{g p m}+\gamma_{0} \text { Dchapter }_{g m}+v_{g m}
$$

Note that now the coefficient on PTA should be positive or more negative than 1.0 if MFN and PTA tariffs are substitutes (i.e. $\beta>1$ or $\beta<0$ ), while it should be negative and greater than -1.0 if they are complements $($ i.e. $0<\beta<1)$. The inequality constraint is that the left hand side cannot be negative, so we estimate this with Tobit.

Since our manipulation of the regression equation allows us to deal with zeros, we use the full data set, i.e. including the tariff lines with MFN zero rates.

The results, shown in the first column of Table 9, reveal that the treatment of zeros does affect the point estimates, but does not alter the baseline inference that MFN and PTA tariffs are complements. In particular, the implied estimate of $\beta$ is 0.46 which is smaller than the 0.94 from the first column of Table 8 . However $\beta$ is still statistically positive (and lower than one), since our estimate of $\beta-1$ is negative and greater than -1 at the $1 \%$ level. For comparison, we also show that estimate

Table 9. Regressions of MFN-PTA on PTA (All Observations)

\begin{tabular}{cccccccc}
\hline & $\begin{array}{c}\text { Pooled } \\
\text { Tobit }^{(1)}\end{array}$ & $\begin{array}{c}\text { Pooled } \\
\text { OLS }\end{array}$ & $\begin{array}{c}\text { Random } \\
\text { Effects }\end{array}$ & $\begin{array}{c}\text { Fixed } \\
\text { Effects }\end{array}$ & $\begin{array}{c}\text { Pooled } \\
\text { Poisson }\end{array}$ & $\begin{array}{c}\text { Fixed } \\
\text { Effects } \\
\text { Poisson }\end{array}$ & $\begin{array}{c}\text { Random } \\
\text { Effect Poisson }\end{array}$ \\
\cline { 2 - 7 } PTA & $-0.54^{*}$ & $-0.06^{*}$ & $-0.057^{*}$ & $-0.057^{*}$ & $-0.091^{*}$ & $-0.117^{*}$ & $-0.117^{*}$ \\
& $(0.0019)$ & $(0.0012)$ & $(0.0013)$ & $(0.0013)$ & $(0.0009)$ & $(0.0001)$ & $(0.0001)$ \\
Constant & -2.13 & 3.07 & 3.74 & 3.07 & 1.26 & & 1.52 \\
$\begin{array}{c}(0.047) \\
\text {-squared } \\
\text { overall }\end{array}$ & 0.02 & $0.019)$ & $(0.54)$ & $\begin{array}{c}(0.018) \\
(0.006)\end{array}$ & & $(0.13)$ \\
\hline
\end{tabular}

Notes: Standard errors in brackets. A * means that the coefficient is statistically greater than -1 at the $1 \%$ level of significance. Number of clusters (country) $=23$; number of obs. 1,430,933. Coefficients for chapter dummy variables not reported. ${ }^{(1)}$ Standard errors are corrected for heteroschedasticity. (1) 821,320 left-censored observations at 0 . Chapter dummies not reported. 
Table 10. Developed and Developing Nation Samples (Tobit Estimation of MFN-PTA)

\begin{tabular}{ccccccc}
\hline & \multicolumn{3}{c}{ Developed Countries } & \multicolumn{3}{c}{ Developing Countries } \\
\cline { 2 - 6 } & Coefficient & s.e. & $P>t$ & Coefficient & s.e. & $P>t$ \\
\cline { 2 - 6 } Preferential tariff & $-0.22^{*}$ & 0.0046 & 0.0 & $-0.795^{*}$ & 0.0022 & 0.0 \\
Constant & -9.49 & 0.093 & 0.0 & 2.70 & 0.05 & 0.0 \\
R-squared overall & 0.02 & & & 0.04 & & \\
Countries & 7 & & 16 & \\
Observations & 506,$333 ; 340,684$ left-censored & 924,$600 ; 480,636$ left-censored \\
\hline
\end{tabular}

Notes: Standard errors in brackets. A * means that the coefficient is statistically greater than -1 at the $1 \%$ level of significance. Chapter dummies not reported.

using the other estimators. In all cases, the estimate of $\beta-1$ is statistically negative and larger than -1.0. We note that the Poisson estimators do converge and they yields point estimates that are in line with the others.

Table 10 shows the results with all observation and Tobit estimation of eq. (7) for developed and developing nations separately. Apart from reducing the slope estimates the results are qualitatively similar to those of Table 6.

\section{Concluding Remarks}

If regionalism has hindered MFN tariff cutting in an important way over that past decades, we should observe the highest MFN tariffs in the products where PTA tariffs are the lowest, i.e. MFN and preferential tariffs should be substitutes. An examination of tariff-line data for a broad range of nations finds exactly the opposite. The products where nations have chosen high MFN tariffs, they have granted few preferences. Likewise at the national level, the operation of the stumbling bloc logic should have produced a pattern whereby nations that participated in regionalism should have higher MFN tariffs than those that have not. Again the data for a broad range of nations contradicts this. In fact, the data show that MFN and PTA tariffs are complements, not substitutes. These results support, using level data, the conclusion of Estevadeordal et al. (2008) that the ongoing regionalism trend does not harm multilateral trade liberalization. Our paper does not propose or estimate a structural model, but the results hint at an underlying mechanism that rejects the framing of the question that is standard in the stumbling/building bloc approach. One interpretation of our findings is that regionalism is neither a building nor a stumbling bloc. Rather, political-economy factors produce forces that simultaneously influence the selection of MFN and PTA 
tariffs. In the nations and sectors where a political consensus has been marshalled behind liberal trade policies, tariffs were cut on both an MFN and preferential basis. In other nations and/or sectors where there is a political consensus for protection, tariffs are high both multilaterally and preferentially. In short, it is a third factor - the strength of sectoral vested interests - that determines both the MFN and preferential tariffs. Under this conjecture, the complements effect we observe is not due to regional tariff cutting promoting multilateral tariff cutting; it is due to a third cause.

Clearly a great deal more work needs to be done on this issue. Our paper should be viewed as a tentative step towards using tariff-line data on the level of MFN and preferential tariffs to shed light on the connection between MFN and preferential tariffs. $^{12}$

Received 18 June 2009, Revised 7 February 2010, Accepted 11 February 2010

\section{References}

Baldwin, R.E. (1987), "Politically Realistic Objective Functions and Trade Policy: PROFs and Tariffs", Economic Letters, Vol. 24, pp. 287-90.

Bhagwati, J. (2008), Termites in the Trading System: How Preferential Agreements Undermine Free Trade, Oxford University Press, Oxford.

Estevadeordal, T., L. Freund and E. Ornelas (2008), "Does Regionalism Affect Trade Liberalization Towards Non-members?", The Quarterly Journal of Economics, Vol. 123, pp. 1531-75.

Findlay, R., and S. Wellisz (1982), "Endogenous Tariffs, the Political Economy of Trade Restrictions, and Welfare", in Import Competition and Response (ed.) Bhagwati, J., University of Chicago Press, Chicago.

Finger, J.M. and L. Schuknecht (1999), "Market Access Advances and Retreats: The Uruguay Round and Beyond", World Bank Policy Research Working Paper, No. 2232.

Freund, C. (2000), "Multilateralism and the Endogenous Formation of Preferential Trade Agreements", Journal of International Economics, Vol. 52, pp. 359-76.

Grossman, G.M. and E. Helpman (1994), "Protection for Sale", American Economic Review, Vol. 84, pp. 833-50.

Hillman, A. (1989), The Political Economy of Protection, Harwood Academic Publishers, Chur, London and New York.

\footnotetext{
${ }^{12}$ We thank Alan Winters, Gary Hufbauer and Nuno Limao for comments and assistance. We thank Theresa Carpenter and Andy Lendle for help with the data. Date received June 2009, date accepted October 2009.
} 
Karacavaoli, B. and N. Limão (2008), "The Clash of Liberalizations: Preferential vs. Multilateral Trade Liberalization in the European Union", Journal of International Economics, Vol. 74, pp. 299-327.

Kennan, J. and R. Riezman (1990), "Optimal Tariff Equilibria with Customs Unions", Canadian Journal of Economics, Vol. 90, pp. 70-83.

Krishna, P. (1998), "Regionalism and Multilateralism: a Political Economy Approach", The Quarterly Journal of Economics, Vol. 113, pp. 227-50.

Levy, P. (1997), "A Political-Economic Analysis of Free Trade Agreements", American Economic Review, Vol. 87, pp. 506-19.

Limão, N. (2006), "Preferential Trade Agreements as Stumbling Blocks for Multilateral Trade Liberalization: Evidence for the U.S”., American Economic Review, Vol. 96, pp. 896-914.

Long, N. V. and N. Vousden (1991), "Protectionist Responses and Declining Industries", Journal of International Economics, Vol. 30, pp. 87-103.

Panagariya, A. (1999), "The Regionalism Debate: An Overview”, The World Economy, Vol. 22, pp. 455-76.

Riezman, R. (1985), "Customs Unions and the Core", Journal of International Economics, Vol. 19, pp. 355-65. 